\title{
EFFECT OF ALOE VERA GEL ON ACETAMINOPHEN INDUCED NEPHROTOXICITY IN RATS
}

\author{
HINA MAJID ${ }^{1}$, SALMAN SHAHID ${ }^{2}$, MUHAMMAD SUHAIL ${ }^{3}$, SADIA SHAKEEL ${ }^{1}$, \\ MARIAM ASHRAF ${ }^{1}$, GHAZALA RUBI $^{4}$ \\ ${ }^{1}$ Department of Anatomy, PGMI/AMC/LGH, Lahore, ${ }^{2}$ Department of Public Health, UOL, Lahore, \\ ${ }^{3}$ Department of Anatomy, SZPGMI, Lahore, ${ }^{4}$ Research Department, LGH, Lahore.
}

\begin{abstract}
:
Objective: Acetaminophen is a popular over the counter available pain killer. However, its overdose leads to kidney damage. Aloe vera gel has abundant antioxidants. The research intended to establish the effect of Aloe vera gel on the nephrotoxicity induced by acetaminophen.

Methods: Three groups were made each having six rats. Group A (control) was provided standard diet. Group B was fed with normal pellet diet and on the $8^{\text {th }}$ day rats were injected with $1000 \mathrm{mg} / \mathrm{kg}$ b.w. acetaminophen, mixed in $5 \mathrm{ml}$ of normal saline. Group C was treated with standard pellet diet along with $400 \mathrm{mg} / \mathrm{kg}$ b.w. Aloe vera gel extract. On the $8^{\text {th }}$ day, the rats of this group were injected with acetaminophen, $1000 \mathrm{mg} / \mathrm{kg}$ b.w. dissolved in $5 \mathrm{ml}$ normal saline. Blood samples were collected to measure the levels of creatinine, uric acid and blood urea nitrogen. The kidneys of all rats were removed and studied under light microscope. Glomerular morphometry was done to evaluate the renal morphology.

Results: Aloe vera gel extract produced a significant improvement in the glomerular diameter ( $\mathrm{p}$ value $<0.01$ ). Biochemical markers including blood urea nitrogen and creatinine were improved and uric acid levels were significantly reduced ( $\mathrm{p}$ value $<0.01$ ).

Conclusion: Aloe vera gel extract can serve as an easily available and a safe prospect for the treating nephrotoxicity.
\end{abstract}

Keywords: Acetaminophen, antioxidants, Aloe vera gel, Kidneys, Nephrotoxicity

How to cite this article: Majid H, Shahid S, Suhail M, Shakeel S, Ashraf M, Rubi G . Effect of aloe vera gel on acetaminophen induced nephrotoxicity in rats. Pak Postgrad Med J 2019;30(3): 95-99

This is an Open Access article distributed under the terms of the Creative Commons Attribution License (http://creativecommons.org/licenses/by/3.0), which permits unrestricted use, distribution, and reproduction in any medium, provided the original work is properly cited.

\section{INTRODUCTION:}

Acetaminophen, known as paracetemol, is a commonly used pain killer and febrifuge. ${ }^{1}$ It helps relieve headache and body ache. It is also used to alleviate the postoperative pain and is used as a palliative medicine in patients suffering from cancer. ${ }^{2}$ However, over dosage of paracetemol has the tendency to produce dangerous side effects that may result mainly in hepatic and nephrotoxicity. ${ }^{3}$ Researches advocate that the free acid radicals play a prime role in the renal toxicity produced by acetaminophen. ${ }^{4}$ Oxidative stress vandalizes the biomembranes, denatures the proteins and damages the DNA, hence, causing insults to anatomy of the renal proximal tubulues. ${ }^{5}$

Correspondence to: Hina Majid, Department of Anatomy, Postgraduate Medical Institute/Ameer-ud-Din Medical College/ Lahore General Hospital, Lahore

E-mail: hinamajidmir@gmail.com
Studies are being conducted globally to discover agents that can serve as buffers to organs of the body, including kidneys. ${ }^{6}$ Numerous plants and traditional herbs are used in different regions of the world to alleviate and treat renal problems. ${ }^{7}$

Aloe vera is a evergreen xerophytic plant. ${ }^{8}$ The people of Mexico, China, Greece, Egypt and India used this plant for centuries. ${ }^{9}$ Its use has been mentioned in Homeopathic and Ayurvedic medicine to cure various ailments including asthma, colic, diabetes and skin rashes. ${ }^{10,11}$ The plant possesses antiaging, antimicrobial, antioxidant and antidiabetic properties. ${ }^{12}$ The current research was formulated to assess the role of Aloe vera gel on acetaminophen kindled renal damages.

\section{METHODS:}

It was an experimental trial conducted in the department of Anatomy, PGMI, Lahore. Aloe vera plants were 
procured from a local nursery in Lahore. Leaves of the plant were rinsed with water, dissected longitudinally and mucilaginous jelly was scraped out. $96 \%$ ethanol and distilled water $(50 / 50, \mathrm{v} / \mathrm{v})$ were added to homogenize the gel. ${ }^{13}$. Acetaminophen was purchased from Indus Pharmaceutical Industries.

Eighteen healthy male Wistar rats, weighing 200-250g were procured from the animal house of PGMI and housed in well ventilated laboratory cages with 12 hours day/night cycle. Free access to commercial feed and clean drinking water was provided. After a week of acclimatization, they were randomly sorted into groups A, B, C of 6 rats each.

Control group A, was fed on normal pellet diet for a week and on the 8th day, injected with $5 \mathrm{ml}$ normal saline. The rats in group $\mathrm{B}$, were fed with normal diet and monitored for a week and on the 8th day they were administered intraperitoneal injection of acetaminophen $1000 \mathrm{mg} / \mathrm{kg}$ b.w. mixed in $5 \mathrm{ml}$ of normal saline. ${ }^{14}$ The rats in the experimental group $\mathrm{C}$, were fed with normal diet along with $400 \mathrm{mg} / \mathrm{kg}$ b.w. of aloe vera gel extract daily for a week and on the 8th day they were intraperitoneally injected with $1000 \mathrm{mg} / \mathrm{kg}$ b.w. acetaminophen dissolved in $5 \mathrm{ml}$ of normal saline.

All the rats were euthanized, 48 hours after the injection of acetaminophen. Cardiac puncture was done to obtain the blood samples. $4 \mathrm{ml}$ of blood was collected from each rat. ${ }^{15}$ Biochemical parameters including blood urea, creatinine and uric acid levels were recorded. Both kidneys of each rat were removed and fixed in formaldehyde at room temperature for 48 hours. Tissue processing was done and paraffin blocks were made. Blocks were sectioned, stained with Hematoxylin and eosin stain and examined under light microscope. Software SPSS 23.0 was used for data analysis. Numerical data was represented as mean \pm SEM. Oneway ANOVA was applied for comparison among groups.

\section{RESULTS:}

Biochemical tests: Commercially available kits (Sigma) were employed to estimate the concentration of blood urea nitrogen (BUN), creatinine $(\mathrm{Cr})$ and uric acid, as indicators of renal toxicity.

Table1: Biochemical indicators

\begin{tabular}{llll}
\hline Group & BUN mg/L & Cr mg/L & Uric acid $\mathbf{~ m g / L}$ \\
\hline A & $134 \pm 15$ & $4.28 \pm 0.01$ & $9.8 \pm 0.05$ \\
B & $184 \pm 8^{* *}$ & $5.43 \pm 0.021^{* *}$ & $15.67 \pm 0.05^{* *}$ \\
C & $139 \pm 14$ & $4.348 \pm 0.04$ & $10.15 \pm 0.13^{*}$ \\
\hline$*(\mathrm{P}<0.01)$ & & \\
$* *(\mathrm{P}<0.001)$ & in comparison to control
\end{tabular}

\section{Histological Findings:}

Normal squamous epithelial histology of the renal glomeruli and the Bowman's capsule was observed in group A. The proximal convulated tubules showed normal cuboidal epithelium and presence of prominent brush border. Whereas a well-defined, larger lumen was observed in distal convulated tubules (Figure1).

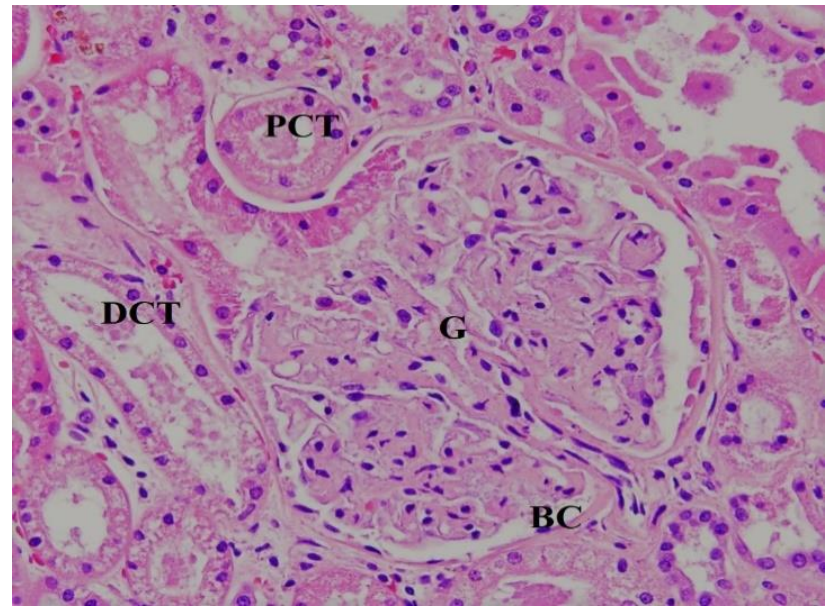

Figure 1: Photomicrograph of kidney of rat belonging to group A showing normal glomeruli $(\mathrm{G})$, Bowman's capsule (BC), proximal convulated tubules (PCT) and distal convulated tubules (DCT) H\&E (200X).

The kidneys belonging to group B revealed congested glomerular capillaries, leukocyte infiltration in the glomerular space and also showed glomerular atrophy. Vacuolization and necrosis was seen in the cells of the tubular epithelium. There was a loss of brush border in the proximal tubules (Figure2).

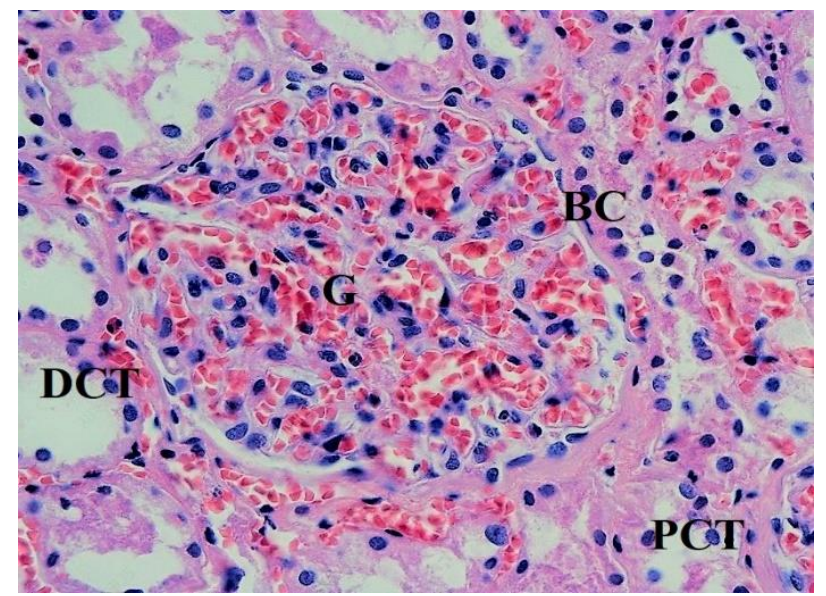

Figure 2: Photomicrograph of kidney of rat belonging to group B showing congested glomeruli (G), Bowman's capsule (BC), proximal convulated tubules (PCT) and distal convulated tubules (DCT) H\&E (200X). 
The kidneys of treated group $\mathrm{C}$ showed reduction of congestion in glomerular capillaries and presented normal histologic features of glomeruli, proximal and distal convoluted tubule. There was mild leucocyte infiltration. The proximal tubules displayed normal microvilli forming a brush border, thus indicating normal functioning of the nephrons. (Figure3).

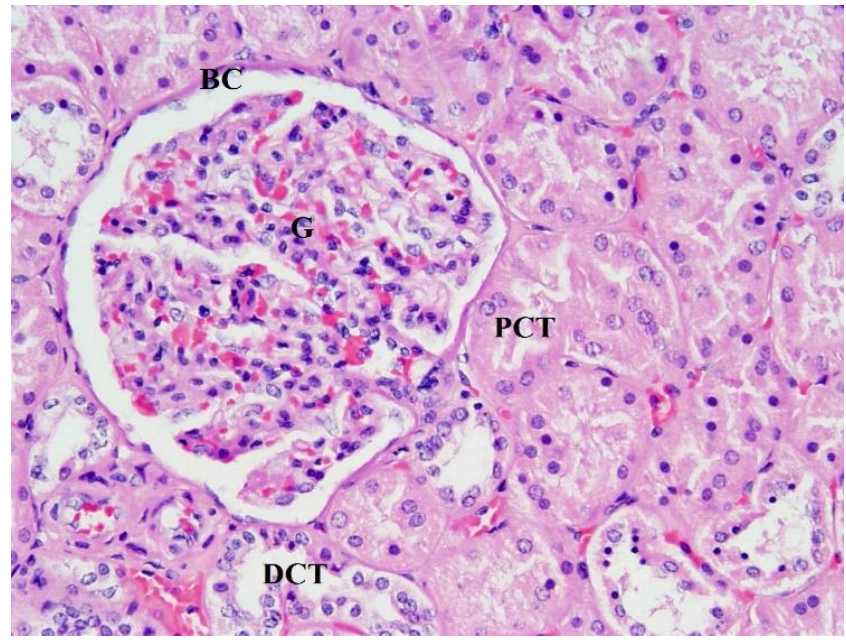

Figure 3: Photomicrograph of kidney of rat belonging to group $\mathrm{C}$ showing normal glomeruli $(\mathrm{G})$, Bowman's capsule (BC), proximal convulated tubules (PCT) and distal convulated tubules (DCT) H\&E (200X).

Glomerular Morphometric Analysis (GMA): The renal morphology was analyzed using glomerular morphometric analysis based on diameter $(\mu \mathrm{m})$ of the glomeruli.

Table 2: Glomerular Morphometric Analysis (Mean \pm SD)

\begin{tabular}{cc}
\hline Group & Diameter $\mu \mathrm{m}$ \\
\hline A & $45.34 \pm 1.94$ \\
B & $33.80 \pm 2.66^{* *}$ \\
C & $48.84 \pm 5.67^{*}$ \\
\hline$*(\mathrm{P}<0.01)$ & $* *(\mathrm{P}<0.001)$ in comparison to control
\end{tabular}

\section{DISCUSSION:}

Acetaminophen causes organ damage by activating the cascades of reactive oxygen species. ${ }^{15}$ Paracetamol accumulates in the kidneys of animals and humans, leading to renal toxicities. ${ }^{16}$ Reports indicate that acetaminophen accelerates apoptosis in the liver and kidney. ${ }^{17}$ Acetaminophen is often reflected by disturbances in the biochemical markers. The prime hallmarks of renal toxicity include blood urea and creatinine levels. ${ }^{18}$ Blood urea nitrogen, is mainly derived from the routine diet in the liver and is eliminated by the kidneys through urine. Whereas, the tissue breakdown produces creatinine in the body. ${ }^{19}$

The current study, showed that acetaminophen produced a considerable rise in the biochemical indicators. These results coincide with the study results of Isik and friends in 2006. They noted a marked increase in the urea and creatinine levels after paracetamol administration in rats. ${ }^{20}$ This rise in biomarkers supports the link between renal toxicity and free radical stress. ${ }^{21}$ The biochemical parameters correspond with the histological findings of tubular atrophy seen in the group B.

Glomerular morphometric analysis of the acetaminophen treated group B showed smaller size and reduced diameter of glomeruli. Vacuole formation was observed among the cells of the renal tubules. The results are in agreement with the experiment conducted by Refaat in 2008. ${ }^{22}$ Acetaminophen induced proximal tubular necrosis and interstitial vascular congestion and extravasation of blood. There was also loss of brush border of proximal convoluted tubule in group B and this supports the nephrotoxicity by acetaminophen referred by other authors who used different doses such as $1000 \mathrm{mg} / \mathrm{kg}^{14}, 2500 \mathrm{mg} / \mathrm{kg}^{23}, 500 \mathrm{mg} / \mathrm{kg}^{24}, 750$ $\mathrm{mg} / \mathrm{kg}^{25}$.

Reactive oxygen species have been implemented in nephrotoxicity. ${ }^{26}$ Several agents that scavenge or interfere with the production of reactive oxygen species have been used to ameliorate nephrotoxicity. ${ }^{27}$ Glomerular analysis and biochemical tests were significantly imoproved in Aloe vera treated group C. The plant gel is known to enhance the activity of antioxidant enzymes and prevent lipoperoxidation. Ramachandraiahgari and his friends also documented the protective role of Aloe vera against renal damage. ${ }^{28}$ The present study extends the beneficial role of Aloe vera gel extract against nephrotoxicity. The plant gel is readily available in the market as a dietary supplement. It is a rich amalgam of polyphenols and flavonoids. Also present are vitamins including vitamin $\mathrm{C}$ and minerals like zinc and selenium which act as powerful free radical scavengers. ${ }^{29}$

Daily pretreatment with Aloe vera gel extract for a week conferred nephroprotection against acetaminophen. The extract provided significant protection against the toxic effects of acetaminophen including glomerular congestion, tubular necrosis and helped to improve the biochemical parameters.

\section{CONCLUSION:}

Aloe vera gel extract provided adequate protection against nephrotoxicity inflicted by acetaminophen. 


\section{ETHICAL APPROVAL}

The study was approved from Ethical Review Committee of Federal Postgraduate Medical Institute/Shaikh Zayd Hospital National Health Research Complex, Lahore, Pakistan, vide reference No. F39/NHRC/Admin/IRB/183 dated August 9, 2016.

\section{REFERENCES:}

1. Bertolini A, Ferrari A, Ottani A, Guerzoni S, Tacchi R, Leone S. Paracetamol: new vistas of an old drug. Fall-Winter. 2006; 12 (4):250-275.

2. Graham GG, Davies MJ, Day RO, Mohamudally A, Scott KF. The modern pharmacology of paracetamol: therapeutic actions, mechanism of action, metabolism, toxicity and recent pharmacological findings. Inflammopharmacology. 2013; 21(3): 201232.

3. Ahmad ST, Arjumand W, Nafees S. Hesperidin alleviates acetaminophen induced toxicity in Wistar rats by abrogation of oxidative stress, apoptosis and inflammation. Toxicol Lett. 2012; 208:149-161.

4. Karthivashan G, Kura AU, Arulselvan P, Isa N, Fakurazi S. The modulatory effect of Moringa oleifera leaf extract on endogenous antioxidant systems and inflammatory markers in an acetaminophen-induced nephrotoxic mice model. PeerJ. 2016; 4:e2127.

5. Sarumathy K. A protective effect of Caesalpinia sappan on acetaminophen induced nephrotoxicity and oxidative stress in male albino rats. IJPI's journal of pharmacology and toxicology. 2011; 1:2.

6. Parthipan M, Thomas B, Rajendran A. Habitat diversity, morphological and systematic analysis of multipotential species of Aloe barbadensis Mill. (Liliaceae) from Southeren Westran Ghats of Tamil Nadu, India. J Res Biol. 2011; 1:237-241.

7. Ra AK, Mohebbati R, Hosseinian S. Drug-induced nephrotoxicity and medicinal plants. Iran J Kid Dis. 2017; 11:169-179.

8. Mohamed EK. Antidiabetic, Antihypercholestermic and Antioxidative Effect of Aloe Vera Gel Extract in Alloxan Induced Diabetic Rats. Aus J Basic Appl Sci. 2011; 5(11):1321-1327.

9. Mehta I. History OF Aloe Vera - (A Magical Plant). IOSR-JHSS. 2017; 22(8):21-24.

10. Guven M, Gölge UH, Aslan E, Sehitoglu MH, Aras $\mathrm{AB}$, Akman T, et al. The effect of aloe vera on ischemia-Reperfusion injury of sciatic nerve in rats. Biomed Pharmacother. 2016; 79:201-207.

11. Bhuvana KB, Hema NG, Patil R. Review on Aloe Vera. IJAR. 2014; 2(3): 677-691.

12. Barmak MJ, Khaksar Z, Sharifi A, Mahmoudi R. Effect of Aloe Vera extract on ovaries development in during gestational age of 18 day embryo of diabetic rats. Life Sci J. 2013; 10(2s):323-327.
13. Gulnaz H, Tahir M, Sami W. Protective Effects of Garlic Oil on Acetaminophen Induced Nephrotoxicity in Male Abino Rats. Biomedica, 2010; 26(7): 9-15.

14. Reshi MS, Shrivastava S, Jaswal A, Sinha N, Uthra C, Shukla S. Gold nanoparticles ameliorate acetaminophen induced hepato-renal injury in rats. Exp Toxicol Pathol. 2017; 69:231-240

15. Murad HAS, Habib H, Kamel Y, Alsayed S, Shakweer M, Elshal M. Thearubigins protect against acetaminophen-induced hepatic and renal injury in mice: biochemical, histopathological, immunohistochemical, and flow cytometry study. Drug Chem Toxicol. 2016; 39:190-198.

17. Wang Z, Hu J, Yan M, Xing JJ, Liu WC, Li W. Caspase mediated anti-apoptotic effect of ginsenoside $\mathrm{Rg} 5$, a main rare ginsenoside, on acetaminophen-induced hepatotoxicity in mice. J Agric Food Chem. 2017; 65:9226-9236.

18. Abd-Algader NN, EL-Kamali HH, Ramadan MM. Xylopiaaethiopica volatile compounds protect against Panadol-induced hepatic and renal toxicity in male rats. World App Sci J. 2013; 20(2):78-88.

19. Baxmann AC, Ahmed MS, Marques NC, Menon VB, Pereira AB, Kirsztajn GM, et al. Influence of muscle mass and physical activity on serum and urinary creatinine and serum cystatin C. Clin J Am Soc Nephrol. 2008; 3:348-354.

20. Isik B, Bayrak R, Akcay A. Erdosteine against acetaminophen induced renal toxicity. Molecular Cell Biochemistry. 2006; 287: 185-191.

21. Qasim B, Mohammed NM, Abd AH. The nephroprotective effects of vardenafil against amikacin induced nephrotoxicity in rabbits. Int J Adv Res. 2014; 2:747-755.

22. Refaat SH, Mady AA. Vitamin A against the Acetaminophen- induced toxicity in the renal cortex of Albino Rats. Egypt J Histol. 2008; 31(2): 321-331.

23. Fouad AA, Yaacoubi MT, El-Bidawy. Therapeutic potential of hemin in acetaminophen induced nephrotoxicity in rats. Eviron. Toxicol. Pharmacol. 2009; 27: 277-282.

24. Khorsandi L, Orazizadeh M. Protective effect of Curcuma longa extract on acetaminophen induced nephrotoxicity in mice. DARU. 2008; 16(3): 155159.

25. Abdel-Zaher AO, Abdel-Hady RA, Mamoud MM, Farrag MMY. The potential protective role of alphalipoic aid against acetaminophen - induced hepatic and renal damage. Toxicol. 2008; 243: 261-270.

16. Czerska M, Mikołajewska K, Zieliński M, Ojha S, Sonker K, Pandey M, Saraf SA. Aloe vera gel: A potent nutraceutical. J Nat Pharm. 2011; 2:36-39.

26. Gromadzińska J, Wąsowicz W. Today's oxidative stress markers. Med Pr. 2015; 66:393-405. 
27. Rafieian-kopaei M. Medicinal plants for renal injury prevention. J Renal Inj Prev. 2013; 2(2): 63-65.

28. Ramachandraiahgari RMY, Somesula SR, Adi PJ, Mannur IS, Enamalaa M, Matcha B. Protective role of ethanolic extract of aloe vera antioxidant properties on liver and kidney of streptozotocininduced diabetic rats. Dig J Nanomater Biostruct. 2012; 7(1):175 - 184 .

29. Mahor G, Ali SA. Recent update on the medicinal properties and use of Aloe vera in the treatment of various ailments. Biosci Biotech Res Comm. 2016; 9(2): 273-288.

\section{AUTHORS' CONTRIBUTION:}

HM: conception, designing, acquisition, analysis and interpretation of data

SS: Manuscript drafting, study design, data collection

MS: Review of article

SS: Literature review

MA: Data interpretation

GR: Statistical analysis 